\title{
Resilient Business Design: Training a reflective business design mindset through design games
}

\author{
Kristina Maria Madsen ${ }^{a^{*}}$, Morten Lund ${ }^{a}$ \\ aAalborg University Business School \\ *Corresponding author e-mail: krma@business.aau.dk
}

\begin{abstract}
:
Facing a future of uncertainty for businesses, design as a process and mindset can allow businesses to become more resilient. However, transforming and working strategically with design thinking and business design requires design skills and design knowledge. In turn, we argue that this requires the development of a reflective business design mindset in non-designer. What we propose, is that design games can facilitate training this mindset and thereby strengthen business design resilience. Design games have shown to be relevant and effective tools for supporting learning and shaping a mindset. In this paper, we discuss the intersection between business design, design thinking, and experiential learning in a design game and training context and exemplify these premises with two different design games. Thus, it is concluded that training through design games can be one approach to create experience-based learning and through active experimentation training, the design mindset can be nurtured.
\end{abstract}

Keywords: design games, business design, innovation, training

\section{Introduction}

Facing a future of uncertainty for businesses, design as a process and mindset can allow organisations to become more resilient in their ability to change their business design (van der Pijl, Lokitz \& Solomon, 2016). Innovation of business design can happen by chance in circumstances of uncertainty, such as we have seen relating to the COVID-19 pandemic (Aagaard \& Nielsen 2021). Nevertheless, transforming and working actively and strategically with design thinking and business design requires design skills (e.g. van der Pijl, Lokitz \& Solomon, 2016; Lewrick, Link \& Leifer, 2018; 2020) and design knowledge (e.g. Cross, 2006).

Formalised processes for business design (Bland \& Osterwalder, 2020; van der Pijl, Lokitz \& Solomon, 2016; Martin \& Martin, 2009) or design thinking (Lewrick, Link \& Leifer, 2018; 2020; Brown, 2009) are often long and time-consuming, thus, longer periods may be necessary for creating real change. In addition, there is an interesting proposal in training the skills and understanding of terminologies, methods, and processes around business design, so that business design innovation becomes a more 
fundamental part of a company's day-to-day operations and not only reserved for prolonged and dedicated business design processes. The argument here is that it is in the continuous, sustained work effort with a company's business design that builds greater strategic resilience in an era of uncertainty. An example of this is provided in Lund \& Nielsen (2014) study of business design overtime in an entrepreneurial start-up, indicating several different business model designs over three years.

From a design perspective, it is relevant to approach this from Schön's (1983) notion of the reflective practitioner. Understood as reflection-in-practice happens in-situ of design or development, such as when an unforeseen consequence occurs in a design process, causing the designer to reframe the situation. Where reflection-on-practice mostly occurs post design, as the designer reflects on what and why something was decided the way it was. Thus, a behaviour we aspire to train in business design, to create more resilient businesses. Moreover, from Schön's notion of the reflection in and on practice, this can from a learning perspective be seen in the light of an experiential learning approach and understanding. Kolb (2015) argues for learning as a continuous process grounded in experiences with the reference to Dewey, Piaget, and Schön's theories on experience-based learning. Nevertheless, experiential learning is not solemnly grounded in reflective practices but includes experiencing, reflecting, thinking, and acting. Thus, moving the mind from an experience to acting on the learned. Therefore, what we propose in this paper is that design games can facilitate business design training to strengthen a company's resilience through continuous development of business design in an era of uncertainty. In this paper, we discuss the intersection between business design, design thinking, and experiential learning in a design game and training context and exemplify these premises with two different design games.

\section{The Magic of Business Design}

From viability in design thinking (Brown, 2009), design of business (Martin \& Martin, 2009), business model creation (Osterwalder \& Pigneur, 2010) to rapid testing of business ideas (Bland \& Osterwalder, 2020) and lean start-up (Ries, 2011), business design takes on many shapes and perspectives within business and design research. Toolbox literature such as 'Design a better business' (Van Der Pijl, Lokitz \& Solomon, 2016) and 'The design thinking Playbook/Toolbox' (Lewrick, Link \& Leifer, 2018; 2020) focus on creating a mindset for working designerly with viability or business. Thus, the key to achieving a designerly approach to business lies in an organisation's mindset towards innovation and how development emerges. Designerly understood as Cross's (2006) definition of knowledge, by making an individual able to both analyse a problem and produce a solution to said problem.

\section{1: From a game-based learning and serious play perspective}

Design games present an arena for training business design terminology, methods and processes. The interest in the potentials of gamification for innovation in businesses (Gudiksen \& Inlove, 2018; Gudiksen, 2015) or for innovating businesses through participant innovation (Jipa \& Marin, 2014; Patricio, 2017; Paravizo et al., 2018) has been an ongoing topic in "games with a purpose" (Deterding et al., 2011a) research for the last decade. Fundamentally, this approach demonstrates the potential of game mechanics and structures to enhance the motivational affordances (Deterding et al., 2011a; Deterding et al., 2011b) in facilitating innovation.

The connection between games and learning is not a new concept, rather it has been widely explored through research areas such as game-based learning and serious play. Game-based learning 
can be defined as a space "[...] where game content and gameplay enhance knowledge and skills acquisition, and where game activities involve problem-solving spaces and challenges that provide players/learners with a sense of achievement." (Qian \& Clark, 2016; p 51). Even though Van Staalduinen \& De Freitas (2011) argued that pedagogy and game design has developed as to separate fields, leaving out how educational games in game-based learning develop together, Qian \& Clark (2016) establish through a review on the recent research on game-based learning that games designed with a focus on both learning strategies and game elements are the most successful. While also stating that design games tend to work better than educational or entertainment games. This begs the question of whether learning might in the process rather than in the game itself?

Serious play refers to a stream of organizational research, which uses "[...] serious play to describe situations in which people engage in playful behaviours deliberately to achieve work-related objectives." (Statler, Heracleous \& Jacobs, 2011; p 236). One of the most known approaches in serious play might be the LEGO serious play, which is referred to as a "language" to unlock or breaking habitual thinking (Kristiansen \& Rasmussen, 2014). This approach to serious play is based on a model moving from 'creating learning' to 'unlocking new knowledge' to 'breaking habitual thinking'. Here Kristiansen \& Rasmussen (2014) describe the serious play process as moving from individual to shared knowledge. Thus, using a game- and playful process to develop a mindset of shared knowledge and space for play. This is also described by Statler et al. (2011; p 237) as the paradox of intentionality of serious play, which is "[...] when people engage deliberately in a fun, intrinsically motivating activity as a means to achieve a serious, extrinsically motivated work objective.". Nevertheless, the literature fails to show how to move beyond "design and facilitate a serious play process to achieve one or several of the outcomes" (Statler et al., 2011). Even though LEGO serious play presents an approach to move beyond habitual thinking and creating shared knowledge a key challenge in serious play is emergence. Statler et al. (2011; p 250) underlines that a key challenge on a theoretical level "[..] is to consider how serious play can and does emerge spontaneously in organizations, whether explicitly in conjunction with some kind of OD [organizational development] intervention or not."

In the LEGO serious play model, Kristiansen \& Rasmussen (2014) point to the importance of managers and employees being aware of emergence, since it is something that cannot be predicted or outlined, and therefore something that must be probed in-situ, learned from and responded to, which leads us back to Schön's reflective practitioner and being able to seize and act upon emerging ideas or innovation in practice while reflecting hereon. Moreover, changing the way we think and understand patterns to be more aware of emerging potentials for business design.

The main point here is that games and play have shown to be relevant and effective tools for learning and shaping a mindset. And when seen from a design perspective, design games have shown great potential in supporting learning. Thus, it can be argued that it is relevant to discuss games, not only in development situations as an ideation tool but for training a business design thinking mindset that in everyday practice can be aware of emerging development potentials.

\section{3: Method: The Magic Circle in Experiential Learning}

Knowing that games can be used as a learning tool it is interesting to explore design games in the sense of a training tool for creating resilience and innovation practices in businesses. Turning back to the notion of experiential learning (Kolb, 2015); learning and sense-making are created through active experimentation and experience with the subject at hand (see figure 1). If we approach the process of training business design from the point of view of experiential learning, the knowledge and understanding of business design come from actively working with it. 


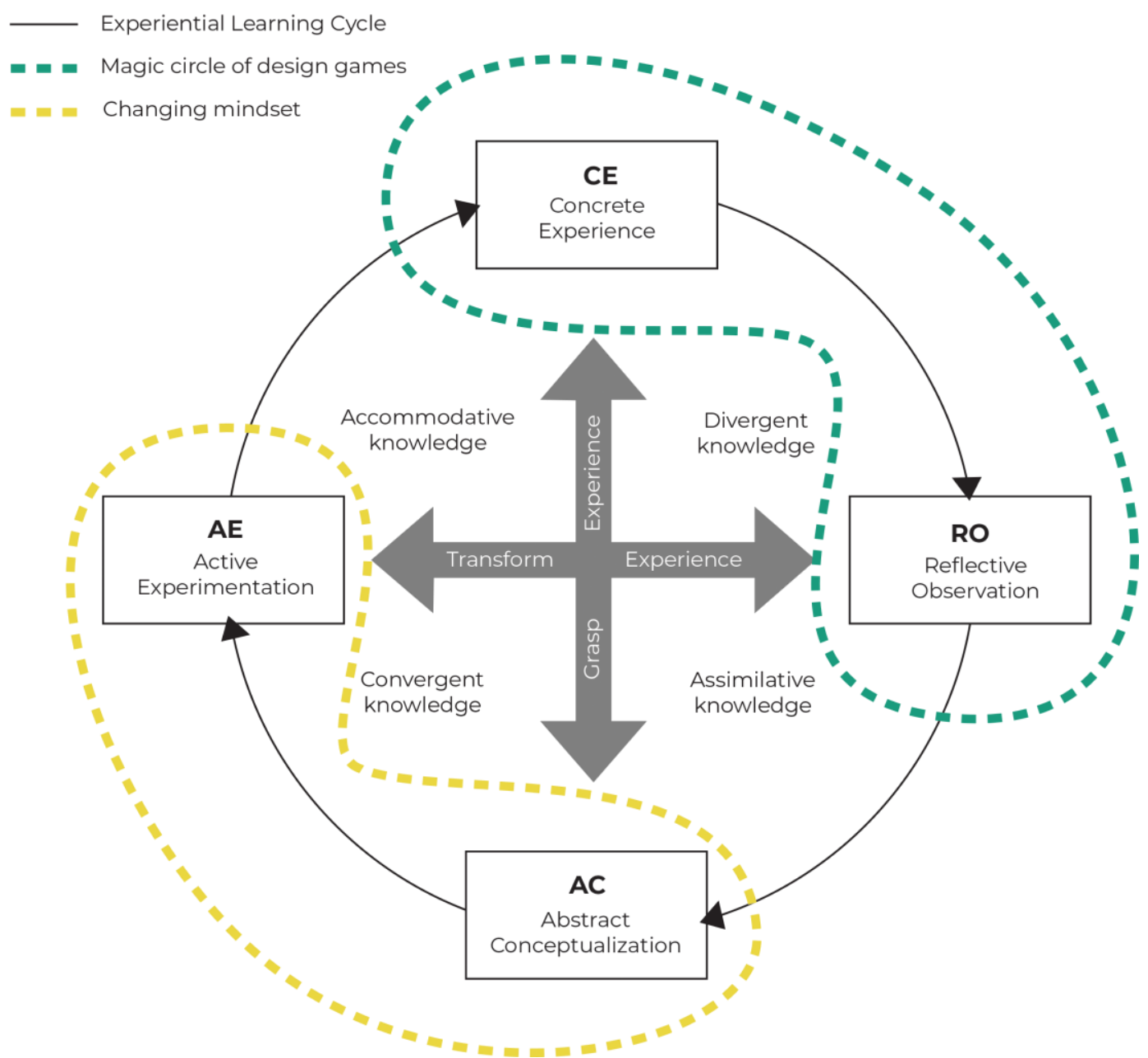

Figure 1: Kolb's (2015) experiential learning cycle, visualising the circular movement between CE, RO, AC and AE (drawn based on the model visualised in Kolb (2015). The green dotted line indicates where the magic circle of the design games is applied. While the yellow dotted line indicates where in the mindset starts to change.

The logic of using design games as a training ground is based on how games can act as a "magic circle" (Salen, Tekinbaş \& Zimmerman, 2004). The Magic Circle is a core concept in game design that can be explained as the space in which a game takes place (Salen et al., 2004). The magic circle formalizes the game space in which game rules create a special set of meanings for the players in the game setting and guide the game. In the magic circle, players accept the boundaries of the game rules to experience the pleasure a game can afford. Thus, creating a space for exploring processes, or methods for business design and strategic design thinking.

The purpose of presenting the concept of the magic circle is to start exploring the potentials of games and gamification as the facilitator of training a designerly mindset from the experiential learning perspective. This is based on the argument that a setting including gamification of tools, methods, and techniques can support stakeholders in developing a common interdisciplinary language (Gudiksen \& Inlove, 2018; Madsen \& Rasmussen, 2021) and heighten the innovation potential. Thus, the magic circle of games creates the training ground for experiential learning through generating experience with design methods by the experiences and reflection facilitated in a business design-orientated design game, that leads the way to abstract conceptualisation and active experimentation in practice, which is visualised in figure 1 with the green and yellow dotted line. 


\section{Design Games as a training ground}

As design games have shown great potential in supporting learning (Van Staalduinen \& De Freitas, 2011), it is relevant to approach the training of a business design mindset from a design game perspective. By design games, we refer to games that can be used in the early stages of design processes for innovation and collaboration (Brandt \& Messeter, 2004; Törpel, 2006; Gudiksen \& Inlove, 2018). This can both be gamification of existing design methods or creation of new games based on principles of design. The purpose here is, that the gamification of design methods provides a space, or rather a magic circle where non-designers can playfully experiment with design approaches and through these game experiences training a designerly mindset. Instead of merely introducing individuals to a design approach, process or method, they are asked to play a design game, where they through play are introduced to the context/field.

Design games can be applied for different purposes e.g., Brandt \& Messeter (2004) applying design games as a participatory facilitator in early-stage design processes, Törpel (2006) applying organisational design games for playfully gaming through "as is" situations. Or Gudiksen \& Inlove (2018) who presents different design games for innovation and breaking silos. Thus, design games can be strategical tools applied in a design process e.g., in the empathising and defining phase for mapping "as is" state of business design. Or for divergence in the ideation phase, e.g., with LEGO serious play, to harvest shared knowledge between specialised knowledge. But what we propose is that design games are used for implicitly training a business design mindset by playing for experiential learning through the process of playing rather than playing to create a specific outcome, such as a concept. Below this will be exemplified through two different design games.

\section{1: Cards for loT: Business Model Configurations \& IoT technologies}

Cards for loT (Madsen \& Rasmussen, 2021) is a game designed for exploring and ideating innovative ways to combine business model (BM) configurations with loT (internet of things) technologies. The game is intended as an ideation game introducing players to loT and BM terminology and possibilities through the gameplay, which requires players to combine different BM configurations (Taran et al., 2016) with loT technology. Cards for loT use game mechanics to drive and facilitate the progression and ideation throughout the game.

The game consists of two decks of cards, 71 BM configuration cards (Thomsen, Sort \& Kristiansen, 2019) and 64 loT technology cards, a set of rules with multiple game mechanics such as time constraints and tokens for voting for the best business ideas, adding new cards and a joker token to save trashed ideas (see figure 2). Cards for loT use these mechanics to guide participants through five rounds of creating business ideas. In an End Game round, the players will vote on the best business idea created. The game can be played multiple times or at different stages of the design process.

Cards for $10 T$ presents its players' terminology and examples of both business model configurations and IOT technologies while forcing the players to combine these in every which way they find interesting, with no limitations to the economy, technological development, and existing business model. In this process and gameplay, the players are training their vocabulary and understanding of both business models and loT technology, while also training an ideation and innovation mindset looking for potentials and opportunities, without limiting themselves. 


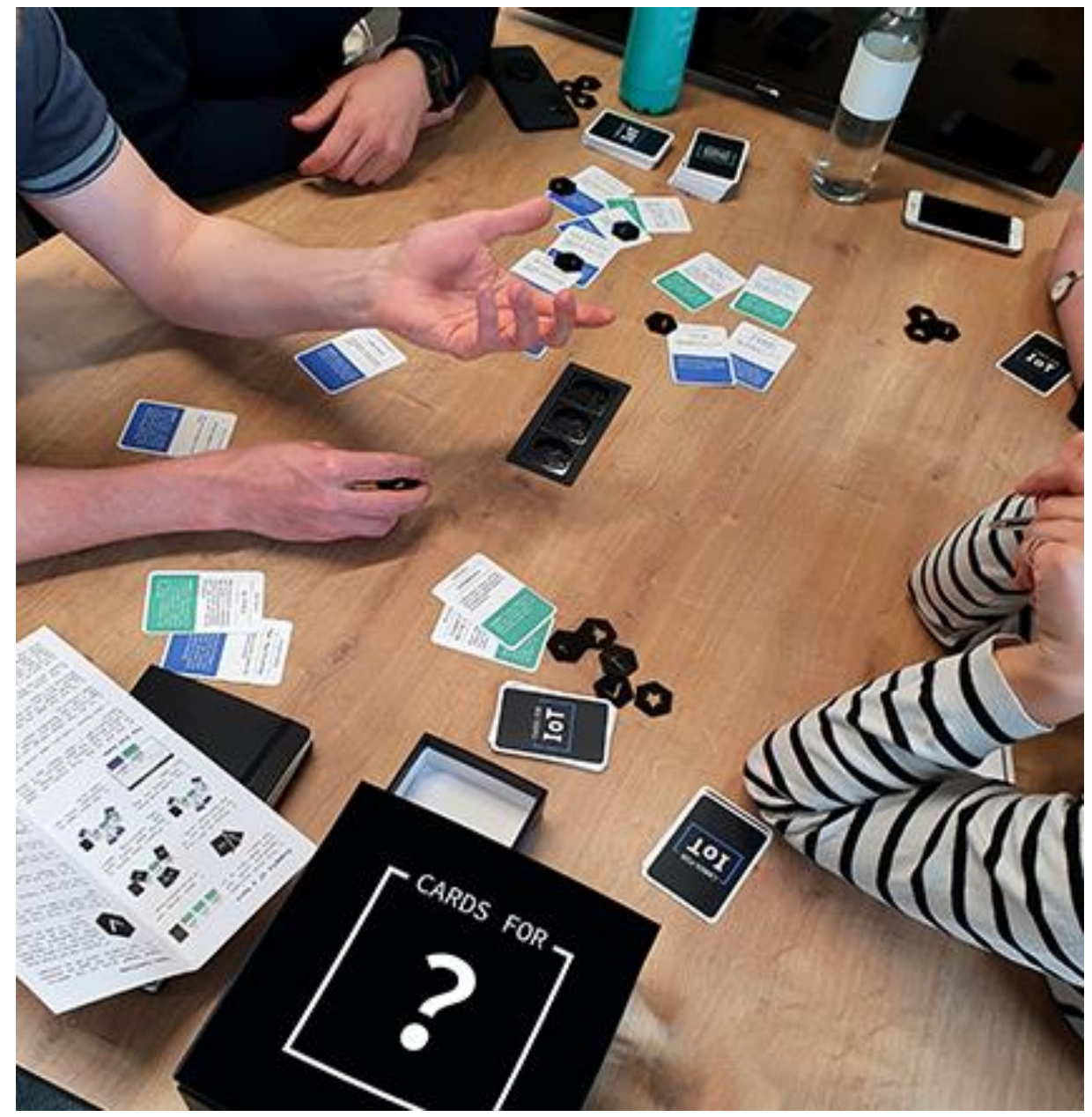

Figure 2: Cards for loT at play.

In each game session 12 to 25 business ideas are developed, where of up five are chosen to be further discussed in a "End Game" phase. In the end game the players discussed the viability, feasibility and desirability of the chosen ideas before voting for a winning idea. Nevertheless, the game does not provide a phase, where the players can discuss development, test and evaluation of the business ideas. Which is something the players have requested, when reflecting on the design game and game sessions. While underlining, that the game has given them new insights, perspectives and ideas on how they can apply loT and business design in the company and therefore, would want the game to provide an additional phase for planning next steps.

\section{2: The Our Museum Game: User centred exhibition design}

The Our Museum Game (Madsen \& Krishnasamy, 2020) is designed as a game for the innovation of interactive museum communication. The game is intended as a user-centred collaborative dialogue game, one that brings together different professions to discuss new ways to communicate to their users based on the users' challenges. The Our Museum Game uses game mechanics to drive and facilitate the progression and ideation throughout the game while being supported by questions to drive dialogue.

The game consists of a game board (see figure 3), a set of rules with multiple game mechanics, such as time constraints, tokens, and roles (Madsen \& Krishnasamy, 2020). The Our Museum Game uses these mechanics to guide participants through three design stages: define, design, and evaluate, 
thereby facilitating and visualizing a process of ideas, discussions, and choices rather than just being a game.

The Our Museum Game asks its players to play through a user-centred miniature design process focusing on creating innovative solutions for a given user segment, while also reflecting on how these designs can be tested and evaluated, to keep learning and refining exhibition and communication design for museum experiences. In this process and gameplay, the players are training their understanding of problem-definition and problem-solving, which are central in the design thinking process. The players are forced to change their practice and process around defining what creates value for the users and what the organisation's value proposition is.

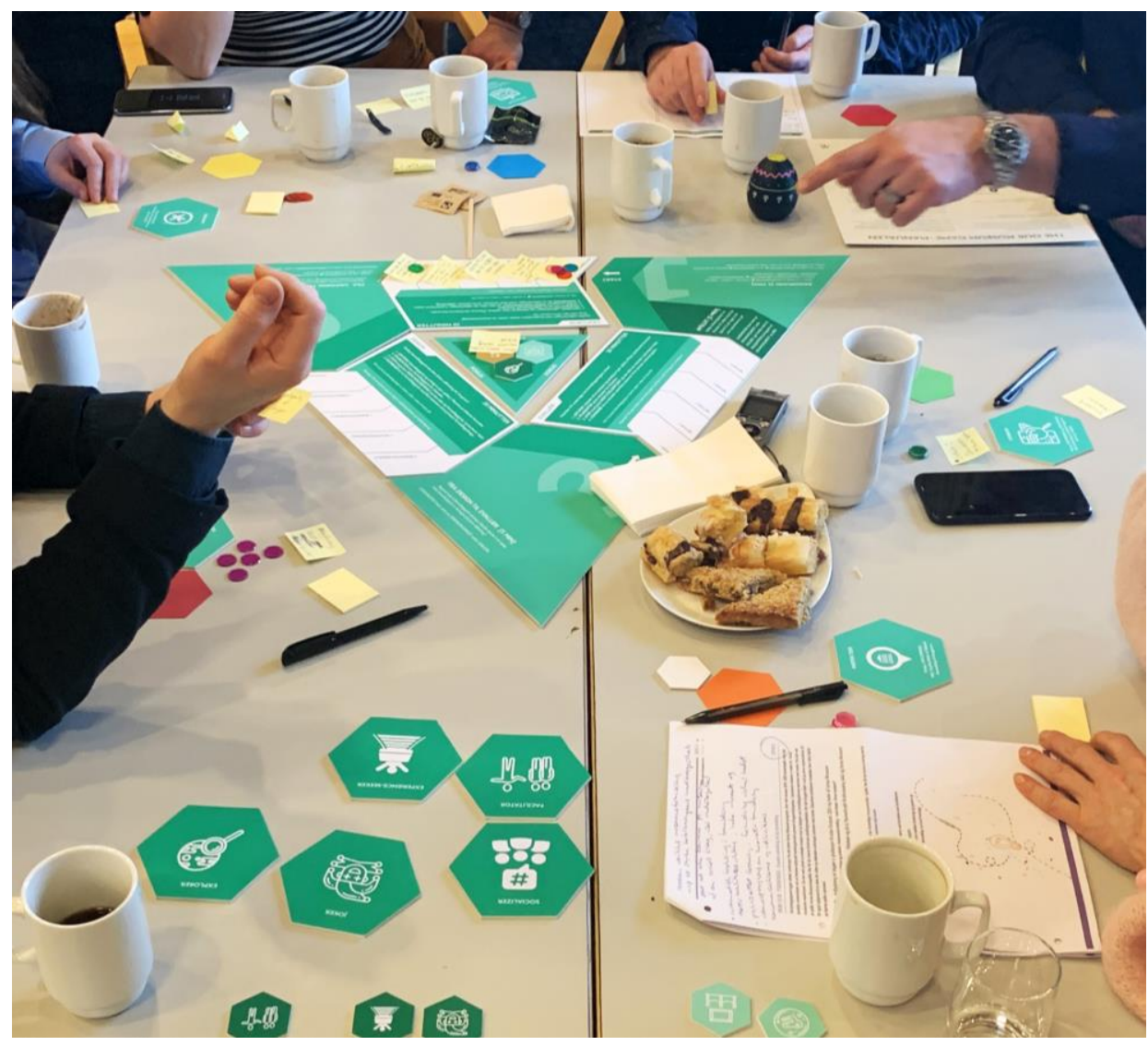

Figure 3: The Our Museum Game at play.

In this game the players end up with a plan for solving two specific user challenges with a design and evaluation approach. Through the game there is defined up to five different user challenges, five design solutions and five evaluation methods. Part of the game is to vote for the most interesting suggestion in each of the games three design stages. One of the major reflections of the players, where that the different game mechanics helped the players think outside of their own biases and professions, while also forcing them to think of design and dissemination potentials from a user perspective, instead of from an expert mindset. Most commonly the players wanted to go back to their respective museums and test out the ideas created, but in a smaller scale or with a different topic, then defined in the game session. 


\section{3: Training ground}

The above games represent examples of design games that through the gameplay supports a design thinking approach and process, thus, presenting its players with a space to think differently about the way they create new business ventures or innovate their current business design. These games act as playgrounds for both ideation and training a reflective design mindset. Furthermore, the games do not need to be implemented into a design process, but rather they can be played at any time and thereby provide a playground for continuous training of the reflective design mindset. Nevertheless, the key here is continuously because the habitual thinking (Kristiansen \& Rasmussen, 2014) will not be broken and transformed into a reflective design mindset by playing the game once. Changing a mindset takes time and practice, and therefore it is relevant to think of training through design games as a continuous process, where different design games are played in a continuous loop of the experiential learning cycle, to keep developing a reflective business design mindset and have the players become more aware of emerging potentials and move beyond design and facilitation serious play sessions (Statler et al., 2011).

\section{Discussion \& Conclusion}

Through the discussion of the intersection between business design, design thinking, and experiential learning in a design game and training context, we argue that training the business design mindset in a company is important. Especially if the goal is to design resilient businesses, it is central to maintain a continuous training of this mindset. We find evidence that this keeps a company going on developing, rethinking, and testing business ideas.

Training through design games can be one approach to create experience-based learning and through active experimentation training, the design mindset can be nurtured. By embedding this mindset, the potential for innovation and seeing new potentials in desirability, viability and feasibility can be supported. Thus, expanding the theoretical field between designerly practices (Schön, 1983; Cross, 2006) and business design thinking toolbox literature (van der Pijl et al., 2016; Lewrick et al., 2018; 2020; Bland \& Oswerwalder, 2020) through the notion of design games providing an experiential training ground for obtaining a business design mindset.

On a practical level, design games, such as Cards for loT and the Our Museum Game, can disarm resistance against change, through the means of creating a magic circle for play. The incentive here is, if a company introduces design games as an approach to informally playing with development processes, terminologies, and concepts, new ways of innovation are introduced, and gradually these will support a mindset development that captures emerging innovation potentials to a much greater degree. In turn, this is expected to support a more resilient and sustainable evolution of businesses and their concrete business design.

This study discusses the potentials in the intersection between business design thinking and design games from a theoretical standpoint, reflected in the potentials of the two design game examples. However, the study is limited in empirical evidence in the long-term shaping of a designerly mindset. A perspective to be further explored through e.g., a longitudinal study exploring the development and effect of shaping a business design mindset through continuously playing with design games. 


\section{References}

Aagaard, A. and Nielsen, C. (2021), The Fifth Stage of Business Model Research: The Role of Business Models in Times of Uncertainty, Journal of Business Models, Vol. 9, No. 1, pp. 77-90.

Brandt, E., \& Messeter, J. (2004). Facilitating collaboration through design games. In Proceedings of the eighth conference on Participatory design: Artful integration: interweaving media, materials and practices-Volume 1 (pp. 121-131).

Brown, T. (2009). Change by design: how design thinking transforms organizations and inspires innovation. New York, NY: HarperBusiness.

Cross, N. (2006). Designerly Ways of Knowing. Springer

Deterding, S., Sicart, M., Nacke, L., O'Hara, K., \& Dixon, D. (2011a). Gamification: Using game-design elements in non-gaming contexts. In CHI'11 extended abstracts on human factors in computing systems (pp. 2425-2428).

Deterding, S., Dixon, D., Khaled, R., \& Nacke, L. (2011b). From game design elements to gamefulness: defining" gamification". In Proceedings of the 15th international academic MindTrek conference: Envisioning future media environments (pp. 9-15).

Gudiksen, S.K., Inlove, J. (2018). Gamification for business: Why innovators and changemakers use games to break down silos, drive engagement and build trust. Kogan Page.

Gudiksen, S. (2015). Business model design games: Rules and procedures to challenge assumptions and elicit surprises. Creativity and Innovation Management, 24(2), 307-322.

Jipa, G., \& Marin, I. (2014). Enterprise gamification in business to consumer (B2C) engagement model. In Proceedings of the 8th International Management Conference "Management Challenges for Sustainable Development (pp. 489-496).

Kolb, D. A. (2014). Experiential learning: Experience as the source of learning and development. FT press.

Kristiansen, P., \& Rasmussen, R. (2014). Building a better business using the Lego serious play method. John Wiley \& Sons.

Lewrick, M., Link, P., \& Leifer, L. (2018). The design thinking playbook: Mindful digital transformation of teams, products, services, businesses and ecosystems. John Wiley \& Sons.

Lewrick, M., Link, P., \& Leifer, L. J. (2020). The Design Thinking Toolbox: A Guide to Mastering the Most Popular and Valuable Innovation Methods. John Wiley \& Sons, Incorporated.

Lund, M., \& Nielsen, C. (2014). The evolution of network-based business models illustrated through the case study of an entrepreneurship project. Journal of Business Models, 2(1), 105-121.

Madsen, K. M., \& Krishnasamy, R. (2020). Our Museum Game: A Collaborative Game for UserCentered Exhibition Design. I A. Brooks, \& E. I. Brooks (red.), ArtsIT 2019: Interactivity \& Game Creation (p. 427-435). Springer. https://doi.org/10.1007/978-3-030-53294-9_31

Madsen, K. M., \& Rasmussen, M. H. (2021). A Matrix for Gamifying Development Workshops. In A. Brooks, E. I. Brooks, \& D. Jonathan (red.), Interactivity \& Game Creation: 9th EAI International Conference, ArtsIT 2020 (vol 367, p. 180-197). Springer. https://doi.org/10.1007/9783-030-73426-8_10

Martin, R., \& Martin, R. L. (2009). The design of business: Why design thinking is the next competitive advantage. Harvard Business Press.

Muller, M.J., Druin, A. (2007). Participatory Design: The Third Space in HCl. 70.

Osterwalder, A., \& Pigneur, Y. (2010). Business model generation: a handbook for visionaries, game changers, and challengers. John Wiley \& Sons.

Bland, D. J., \& Osterwalder, A. (2020). Testing business ideas: A field guide for rapid experimentation. John Wiley \& Sons.

Patricio, R. (2017). A gamified approach for engaging teams in corporate innovation and entrepreneurship. World Journal of Science, Technology and Sustainable Development. 
Paravizo, E., Chaim, O. C., Braatz, D., Muschard, B., \& Rozenfeld, H. (2018). Exploring gamification to support manufacturing education on industry 4.0 as an enabler for innovation and sustainability. Procedia Manufacturing, 21, 438-445.

Qian, M., \& Clark, K. R. (2016). Game-based Learning and 21st century skills: A review of recent research. Computers in human behavior, 63, 50-58.

Reis, E. (2011). The lean startup. New York: Crown Business.

Salen, K., Tekinbaş, K. S., \& Zimmerman, E. (2004). Rules of play: Game design fundamentals. MIT press.

Schön, D. A. (1983/2016). The reflective practitioner: How professionals think in action. Routledge.

Statler, M., Heracleous, L., \& Jacobs, C. D. (2011). Serious play as a practice of paradox. The Journal of Applied Behavioral Science, 47(2), 236-256.

Taran, Y., Nielsen, C., Montemari, M., Thomsen, P., \& Paolone, F. (2016), Business model configurations: a five- $\mathrm{V}$ framework to map out potential innovation routes. European Journal of Innovation Management, Vol. 19, No. 4, pp. 492 - 527.

Thomsen, P., Sort, J. C., \& Kristiansen, K. B.. Booster Cards: A Practical Tool for Unlocking Business Model Innovation. Journal of Business Models, 7(3), 131-142. (2019).

Törpel, B. (2006). The design game in participatory design and design education: chances, risks and side effects. In Proceedings of the ninth conference on Participatory design: Expanding boundaries in design-Volume 1 (pp. 77-86).

Van Der Pijl, P., Lokitz, J., \& Solomon, L. K. (2016). Design a better business: New tools, skills, and mindset for strategy and innovation. John Wiley \& Sons.

Van Staalduinen, J. P., \& De Freitas, S. (2011). A game-based learning framework: Linking game design and learning. Learning to play: exploring the future of education with video games, 53, 29.

Author Bios:

Kristina Maria Madsen, Ph.D., is an assistant professor at Aalborg University Business School with a research interest in business design thinking and game-based methods. Kristina's research focuses on exploring games as a strategic design tool for co-creation and innovation in business design.

Morten Lund, Ph.D., is an associate professor at Aalborg University Business School, Denmark. Morten's research focuses on business model narratives, and business design. Morten is the co-founder of the Business Design Center at Aalborg University Business School. 